\title{
Research on the Influence of Basketball Technique Model on the Comprehensive Quality of Basketball Players
}

\author{
Kaihua $X u^{1}$, Yali Xu \\ ${ }^{1}$ Police Training Management Department, Jiangxi People's Police College, Nanchang, 330103, \\ China \\ ${ }^{2}$ School of Physical Education, Jiangxi University Of Traditional Chinese Medicine, Nanchang, \\ 330004, China
}

Keywords: basketball technology model; basketball player comprehensive quality; influence; research

\begin{abstract}
With the continuous progress of society and the development of globalization, the life of our people has also changed a lot. Of course, these changes are reflected in the cost of eating and learning and learning, many aspects of our daily lives have been affected. Which is also a way to exercise, there are many young people are very concerned about the NBA or CBA, for basketball is very love. Basketball is not our local movement in China, but from abroad to introduce a movement. And this kind of sport is now very popular in all kinds of high efficiency. And often organize some league or friendly to develop the sport in the efficient popularity. But the basketball game winning and losing and the overall quality of basketball players are very close relationship. Colleges and universities often have a dedicated basketball coach to train basketball players, but the overall quality of basketball players is multifaceted, although the instructor's guidance is very important, but the basketball player's own factors can not be ignored. Which is relatively large impact on the overall quality of basketball players basketball technology, of course, far from mobilization of their own physical fitness, mental health and teamwork for the overall quality of basketball players is also a great impact. Only a basketball player to achieve a certain level of overall quality, he can play in the basketball game even better. In order to speed up the development of basketball players, people have made in-depth research on the basketball technology of athletes, and the establishment of a basketball technology model to help them improve their basketball technology, and thus improve their overall quality, then we will specifically explore the analysis of this The rationality of the practice, that is, the basketball technology model for the overall quality of basketball players.
\end{abstract}

\section{Introduction}

Basketball technology is very basic for a basketball player, and only has a good technology to play on the field to play, on the one hand can use these skills to resist the other team's attack, on the other hand can also help their team to be more perfect The attack. So basketball technology is very important for basketball players, basketball players is a very important quality of a comprehensive content. But because the overall quality of basketball players is a lot of aspects, such as basketball players physical fitness, psychological quality, team spirit and their own basketball technology. So what is the impact of basketball technology on the overall quality of basketball players? Today we will carefully analyze and explore. 


\section{The Establishment and Development of Basketball Technology Model}

Basketball technology is one of the aspects of the overall quality of basketball players, the impact of basketball and the results of the game are very large, in order to better practice basketball player personal basketball technology, and its associated basketball researchers specifically established A basketball technology model, then we have to specifically explore the analysis of basketball technology model of the establishment and development.

\section{The Establishment of Basketball Technology Model}

Basketball in China is the reform and opening up after the gradual development, and basketball in China, although many people began to be interested in their participation, but for basketball experience is very small, especially for basketball technology there is a lot of lack of knowledge. And basketball is the Olympic Games of the Olympic Games, in order to prove the strength of our country, we must continue to cultivate talents, but the sport must first be developed to attract more people. But the development of basketball first of all to train some of the best talent, and excellent talent is a very good standard of basketball technology, and only have a good basketball technology to better complete the game, people realized that this began to build a basketball technology Model to better teach basketball players some of the better basketball technology to help enhance the basketball technology, and constantly promote the development of basketball in China.

\section{The Development of Basketball Technology Model}

Now our country basketball has been very good in our country, more and more people began to like and even love basketball, and for basketball players more and more demanding, people for their own basketball overall quality requirements are getting higher and higher. Of course, people for their own basketball technology training can also be more effective. Because before the basketball technology model for the teaching of basketball technology has been a good application, so this model is not short of reference for the development. Of course, not only some of the business basketball players through this model to learn to enhance their own basketball technology, many of the larger basketball club will apply this model. Because the superiority of this model, for the promotion of basketball technology is very favorable, and because basketball technology for the overall quality of basketball players is also very large. Many basketball players for the promotion of basketball technology is also very fancy. So the way to enhance the basketball technology - the application of basketball technology model will continue to develop in China.

\section{The overall quality of basketball players}

Above we have repeatedly referred to the overall quality of basketball players, in short, the overall quality of basketball players for basketball games and a wonderful degree of the game there is a very big relationship. But what exactly does the basketball player's overall quality include? Then we have to analyze the specific.

\section{Basketball technology}

Basketball player in the overall quality of the basketball players have to mention the basketball technology. Because the basketball is not a test brute force of a movement, it is a lot of skills for the use of test is very much, that is, I am boring said basketball technology. People who have a good basketball skills, generally in the course of basketball can be more ease with the handling of basketball, and basketball in the test of this is the athlete's ability. But basketball do not pay attention to certain technical skills, consistent reckless is difficult to complete a wonderful game, and will make basketball lose a lot of fun and skill. And an athlete's basketball technique could turn the tide into a game and win more fun for the game. So basketball technology is a basketball player in the overall quality of a very important one. 


\section{Physical skills}

Basketball is not only about the skills, the skill is the game is more exciting, but the basketball player's physical fitness is indeed the premise of basketball. Because any movement is the need to consume physical, especially basketball, basketball, a lot of action for the athletes are required physical fitness, and basketball need to continue in the playground offensive and defensive, and a basketball game continued The time is very long, the athletes need to continue high-intensity exercise, which for basketball players physical fitness requirements is very high. China has a saying that "in order to run the horse fast, do not give the horse to eat grass line", which means that physical fitness is the basis of basketball, so the physical skills will be measured as a comprehensive basketball player in which the quality one.

\section{Psychological quality}

Basketball is generally more competition, once involved in the game, many people will be because the game psychological great fluctuations. So the psychological quality of the impact on the basketball game is also very large, of course, this effect may be positive, it may be a negative impact. Psychological athletes may not be able to participate in the game may be a great psychological fluctuations, this psychological fluctuations are likely to affect the normal play of basketball players, but also very likely to make some basketball players play long, but the general Basketball players psychological instability will generally make basketball players play disorders, so the basketball game may be affected. And the psychological quality of instability may even make basketball players before the pressure is too large, and even for the impact of physical skills are great, and the physical function of the impact of basketball something more big, so the psychological quality is also a measure of the overall quality of basketball players Is a very important one.

\section{Team spirit}

Basketball is a collective project, not a person can be completed, must rely on the cooperation of many people to complete, so the team basketball team is very important and necessary. But the team is a very test of people, which not only requires a certain integration, patience, and the team between each other and cooperation. This requires the training of team spirit, and the cultivation of team consciousness, because only the real recognition of the role of the team in order to better focus on the cooperation between the team, so the overall quality of basketball players in the measurement of an important indicator of the spirit of the team. So in order to enhance the overall quality of basketball players, for the training of team spirit is also very critical.

\section{The Influence of Basketball Technique Model on the Comprehensive Quality of Basketball Players}

Above we have the basketball technology model and the overall quality of basketball players have a profound understanding of the content, then there is a specific relationship between them? Today we have to seriously analyze, especially the analysis of basketball technology model of the overall quality of basketball players.

\section{Basketball technology model to enhance basketball technology, thereby enhancing self-confidence and the overall quality of basketball players}

The basketball technology model is very useful for the promotion of basketball technology, and the promotion of basketball technology can enhance the personal value of basketball players, so that they continue to enrich themselves, so that their confidence in basketball will gradually increase, so that can promote the promotion of basketball technology, The psychological quality of basketball players will gradually increase, so that the overall quality of athletes in two areas have improved, then the overall quality of basketball players is a very big step forward. This is a virtuous circle, the overall quality of basketball players to upgrade, he will be more stringent requirements for their own, for 
basketball technology and other aspects of the requirements for the development of basketball players is very favorable.

\section{Basketball technology model to enhance basketball technology, lay the foundation for teamwork, and thus improve the overall quality of basketball players}

Basketball technology model for the promotion of basketball technology is very favorable, but the basketball team is a team project, there must be teamwork to complete. But teamwork is not a group of skillless people who rely on brute force to complete a game. But the basketball is stressful, if the basketball player basketball technology is very good, then the team will be more perfect cooperation, a group of people who have basketball skills together to complete the basketball game for basketball viewers is also very exciting. And the fun is also very good. This is for the continuous development of basketball is very favorable. So the basketball technology model for the overall quality of basketball players can not be ignored.

\section{Basketball technology model to enhance the basketball technology for basketball players to lay the foundation for the development of comprehensive quality}

In the above, we have analyzed the comprehensive quality of basketball players, including basketball skills, physical skills, psychological quality, teamwork are the standard of comprehensive quality measurement, but different content for the overall quality of the impact is different, the overall quality of basketball Technology is more basic, because the basketball technology is personal skills, personal training the final team to better cooperation, basketball game can be better, so that the basketball technology model can enhance the basketball technology, which is the overall quality of basketball players can be developed Lay a certain foundation.

\section{Summary}

Basketball in China is now very good development, because it has a certain interesting, competitive and other unique features. But the initial development of basketball is not smooth sailing, of which the most powerful means of development is constantly discovering the promotion of basketball technology. Because basketball technology for the overall quality of basketball players are very large impact. In this paper, we understand the specific quality of the specific content of a detailed analysis of the basketball technology model for the overall quality of basketball players, which are a certain relationship between. Basketball technology model for the overall quality of basketball players are more indirect, it is through the promotion of basketball technology, and thus affect the overall quality of basketball in other content, and ultimately combined with other content of the overall impact of basketball players. From the description of this article, we understand the importance of basketball technology for basketball players, so basketball enthusiasts in order to enhance their overall quality of basketball, basketball technology for the promotion is very necessary.

\section{References}

[1] Sun Minzhi, Basketball, Beijing: People's education press,1994

[2] Sun Minzhi,Basketball aspect, Beijing: People's education press,1996

[3] Sun Minzhi, Coach and tactics. Journal of Beijing Sport Teachers College,1998

[4] Zhou Yong, Sports and Science, 1997

[5] Liu Zhiwei, Weng Honghai.Discussion on Improving the Technical Level of Chinese Men 's Basketball Confrontation, Journal of Harbin Physical Education, 1994

[6] Zhang Zhicheng, On the Fast Attack Tactics of Basketball, Shandong Sports Science and Technology, 1994 
[7] Yang Shu, 2000-2001 season NBA big perspective, Sports reference, 2000-10-03

[8] Basketball Advanced Course, People's Sports Press, 2000-10 